\title{
Documenting Migrant Lives of Sugarcane Harvesting Labourers in Maharashtra- Autoethnographic Reflections
}

\author{
Mithunchandra Chaudhari ${ }^{1} \&$ Ruchi Jaggi ${ }^{2}$ \\ ${ }^{1}$ Assistant Professor, Symbiosis Institute of Media and Communication, Symbiosis \\ International (Deemed University), Pune, India. ORCID: oooo-0oo3-1833-3607. Email: \\ mithunchandra.chaudhari@simc.edu \\ ${ }^{2}$ Professor, Symbiosis Institute of Media and Communication, Symbiosis International \\ (Deemed University), Pune, India. ORCID: oooo-0oo2-4118-7671. Email: \\ ruchi.jaggi@simc.edu
}

\begin{abstract}
Physical labour is not respected in India. Farm labourers are one of the most exploited labourers in India, and the world. Every year more than one million unorganised contract labourers, most of them from lower castes, migrate to the sugar belt in Western Maharashtra for around six months where sugar factories are concentrated. With around 200 sugar factories, Maharashtra ranks number one in sugar production in India. The labourers work for twelve or more hours a day and get poor returns. On the other hand, the working and living conditions violate basic human rights (Deshingkar, Start, 2003). Cane cutting is the most laborious farm work where the labourers have to bend for hours, pick up very heavy cane bundles and mount them at risky heights even during the night time. While injuries are very common among these labourers, occasionally, deaths too take place. The most recent reports reveal that the contractors force women labourers to remove their wombs so that they do not menstruate while working and therefore miss work. The number of such women estimates to around 30\%. "Networks working on health and women's issues say unwarranted hysterectomies among poor women in Beed and other places are the result of workrelated pressures imposed on women, plus a grossly unregulated private medical sector and exploitative contractors and sugar factory owners who hire migrant workers" (Chatterjee, 2019). Along with such health hazards, activists claim that women labourers are exploited by the male contractors at the worksite where physical abuse and rapes happen quite often though they are not formally reported. Young children of the labourers also travel with them at the destination leaving their schools and education behind to help their parents in their work to get trapped into the vicious cycle of bonded labour like their parents (making it a generation after generation trap). Marginalised, alienated and vulnerable in the migrated socio-cultural environment, the sugarcane harvesting backward class labourers face livelihood insecurities. Pregnant women and children have to work. Exploitation is both obvious and subtle. Still this seasonal life is a better opportunity for them. The hardly shared realities, including, women's critical health issues, sexual exploitation, rapes among other sensitive issues of their lives are beyond imagination. This paper studies the observations made while making a documentary film (which is an ethnographic exploration) on migrant labourers' challenges. Using an autoethnographic framework on part of the authors, this research paper will attempt to capture their fears, insecurities, subtle voice as well as the silences.
\end{abstract}

Keywords: Migration, Migrant Labourers, Lower Caste People, Women, Removal of Wombs

\section{BACKGROUND}

Tropical countries produce almost $80 \%$ of the world's sugar while India produces around $20 \%$ of the world's total sugar which is a cane sugar. The Indian Sugar industry is the second largest in

(C) AesthetixMS 2020. This Open Access article is published under a Creative Commons Attribution Non-Commercial 4.o International License (http://creativecommons.org/licenses/by-nc/4.o/), which permits non-commercial re-use, distribution, and reproduction in any medium, provided the original work is properly cited. For citation use the DOI. For commercial re-use, please contact editor@rupkatha.com. 
the world and has changed the rural economy phenomenally. The state of Maharashtra ranks number one in sugar production in the country though Uttar Pradesh tops in area. The total sugarcane plantation area in Maharashtra is around 13 to 14 Lac hectors. There are around 200 sugar factories in Maharashtra (173 co-operative factories, rest of them private). Western Maharashtra has the greatest number of factories and cane fields too. That is why it is known as the sugar belt. The districts in the area include: Ahmednagar, Solapur, Pune, Sangli, Satara \& Kolhapur. Sugarcane harvesting work is extremely intensive, skillful and risky too which includes cutting, binding the bundles and loading and transporting it to the factories via bullock carts, trucks and tractors. It is the most laborious farm work where the labourers have to bend for hours, pick up very heavy cane bundles and mount them at risky heights even during the night time. Though the cane is grown in western Maharashtra mostly, the labourers are never from the area, they are mostly from Marathwada (the districts include: Aurangabad, Jalna, Parbhani, Hingoli, Beed, Nanded, Osmanabad and Latur), the most backward region in the state. The Marathwada region is a rain-shadow area of Maharashtra, facing drought-prone situation almost every year. It is the most underdeveloped area in the state. There are around 15 to 16 Lac sugarcane harvesting labourers in Maharashtra. Beed district alone provides four to five Lac labourers. These are informal, contract labourers, most of them from lower castes. The state or sugar factories do not recognize them as formal labourers even when the labour courts have mandated it. Every year for six to eight months these labourers migrate from their region to the sugar belt.

The labourers stay either at sugar factory premises or sugarcane field premises. All of them have make-shift small homes made of plastic, wood etc. They are not provided with electricity or clean drinking water. There are no toilets for $92 \%$ of the labourers; they use open grounds. One pair of two people mostly a husband and wife earn around 500 rupees daily after working for 12 to 16 hours. The couple is also accompanied by their kids in many cases as a helping hand at harvesting site and home. Those who are situated in sugarcane field premises have to migrate internally two to five times in six to eight months. They work in harsh cold, high temperature (winter and summer). There is a high ratio of illnesses among labourers due to unclean drinking water, unhygienic living conditions, non-immunization among children among other reasons. They mostly ignore their health problems.

Women labourers start their day at around $3 \mathrm{am}$. They have to go to toilet and bathe before male labourers wake up. They cook food and take care of accompanying children and cattle. They fetch water, firewood (all the labourers use traditional chulha). They go to the harvesting site to become half part of the work, return home after work in the night and then again cook and finish all daily chores at home. Some of the women are pregnant too. Many women face other serious illnesses but they ignore it. If serious illness occurs, then they go to the private less qualified doctors in the nearby village and get medicines, and resume work. There is no facility of government health center or school for their children in the premises. Children cannot be and are not sent to schools in most of the cases when children between 6 to 14 must be sent to schools according to the Compulsory \& Free Right to Education for all (RTE Act, Government of India, 2010). Otherwise it becomes a punishable offence, the Act says. Some women face domestic violence. There are many cases of women being sexually exploited by the contractors, tractor drivers etc. A very few cases are known to media, most of them unreported. The marrying age of most of the girls is 14 to 16 so that they can become a working pair with their husbands. 

Reflections

Men too are exploited at their work and economically as contractors in many cases take their (extra) share from the labourers. There is an exploitative understanding among all the labourers regarding this. More than $50 \%$ of the labourers are illiterate. Lack of education leads to cane cutting and cane cutting causes dropout from schools among children. The labourers are not united, they are systematically and successfully kept away from labour unions. They are illiterate, poor, lower-class migrants from backward region so they have no voice. Government, sugar factories, their contractors and sub-contractors play a great role in this. All the contracts with the labourers are oral, there is no written record kept by the contractors or the factories. This is how they are an easy prey for the powerful people. There are cases of accidental serious injuries and even deaths at a few places on the work site. The factory does not take its responsibility as the labourers are not their recognized workers. Indian Sugar Mills Association (ISMA), the oldest industrial association in the country established in 1932, does not consider labourers as their main stakeholder. On the other hand, it only considers farmers, millers and consumers as its main stakeholders and works to sustain and protect them against the cyclical nature of the industry. The sugar industry plays a major role in the election politics in rural area. The sugarcane harvester machines are an emerging threat to the labourers. It is feared that they might replace most of them in the next 10 years. Marginalised, alienated and vulnerable in the migrated sociocultural environment, the sugarcane harvesting backward class labourers face livelihood insecurities.

\section{LITERATURE REVIEW}

Shiralkar, Kulkarni, Ghotale, Gholave (2018) study the sugarcane harvesting labourers from Beed district in their Marathi-language book. It studies their caste, social situation, economic challenges, children's education and their unorganized groups. By studying selected villages in Beed. this is a one of its kind in-depth study in recent times. Jugale (2012) illustrates the role of migration in the development of the sugar sector in western Maharashtra. The inference caused brings vital challenge to the migration models. He studies the changing industrial relations of the migrant workers in sugar factories and the role of state government. "Already trapped in a cycle of debt, migrant workers who depend on Maharashtra's sugarcane belt for their livelihood face the threat of being replaced by imported harvesters" (Bunsha, 2002). The children of the labourers are either partially immunized or non-immunized because of the place or time of vaccination not known, unavailability of immunization services at site, inconvenient time of sessions, unaware of need for vaccination etc. (Pakhare, Pawar, Lokhande, Datta, 2014). The quality of life of sugarcane harvesting migrants deteriorates sharply at destination from the nominal quality of life at their source. Seasonal migrants were found worse off on the parameters of quality of life on food intake, housing profile, medical and educational facilities (Deshingkar, Start, 2003). Women cane harvesters have their peripheral place in the system. Their lives at sugar sites are the most difficult and yet least spoken about (Tokle, 2018).

\section{WHY DOCUMENTARY RESEARCH?}

Documentary research has been a staple of social research since its earliest inception. Documentary products are especially important for the ethnographer, providing a "rich vein for analysis" (Hammersley and Atkinson, 1995: 173). Documentary film is a relevant research method. 'In one sense documentary research becomes synonymous with archival research and addresses issues related to the role and use of documents and public and private records. In another sense, 
documentary research produces artifacts and material culture through artistic representation, moving and still imagery, and sound recordings. Documentary has a direct, multi-sensory impact (Spencer, 2011) and this has led to a dual quest to develop documentary as a way of taking hold of reality and as a new form of social persuasion (Nichols, 2016). Documentary underscores an important dimension to theorization and the construction of meaning of a document. Scott (1990) argues quite correctly that textbooks on research methods have generally failed to recognize documentary research method, and have given most of their space to discussions of questionnaires, interviews and participant observation. This bias creates an imbalance that should be rectified.

\section{AUTOETHNOGRAPHIC REFLECTIONS}

"I suggest that shifting women's position in society does not start from changing the law but traditional patriarchal mechanisms in society. It also starts with offering uncanny academic methods for PhD research, such as auto ethnography, with continuity in performance-based acts, with deconstructing the given methods, learning jazz, with regaining a certain freedom in singing, and with spreading the message to a community”. - Hande Çayır (Istanbul Yeni Yuzyil University)

The researcher-cum-documentary-filmmaker has followed the cane harvesting labourers at various places in western Maharashtra for two seasons. These reflections and stories are based on those experiences of meeting and filming them.

Almost every year, at the beginning of the season, there is a strike by the labourers for wage increment. The issues like school and vaccination facility for migrated children, health benefits at government health centres or ration distribution at the village PDC, electricity, clean drinking, better living conditions, and toilet facilities are never at the centre of the demands. The demand of negligible increment is approved and other demands are left to be addressed.

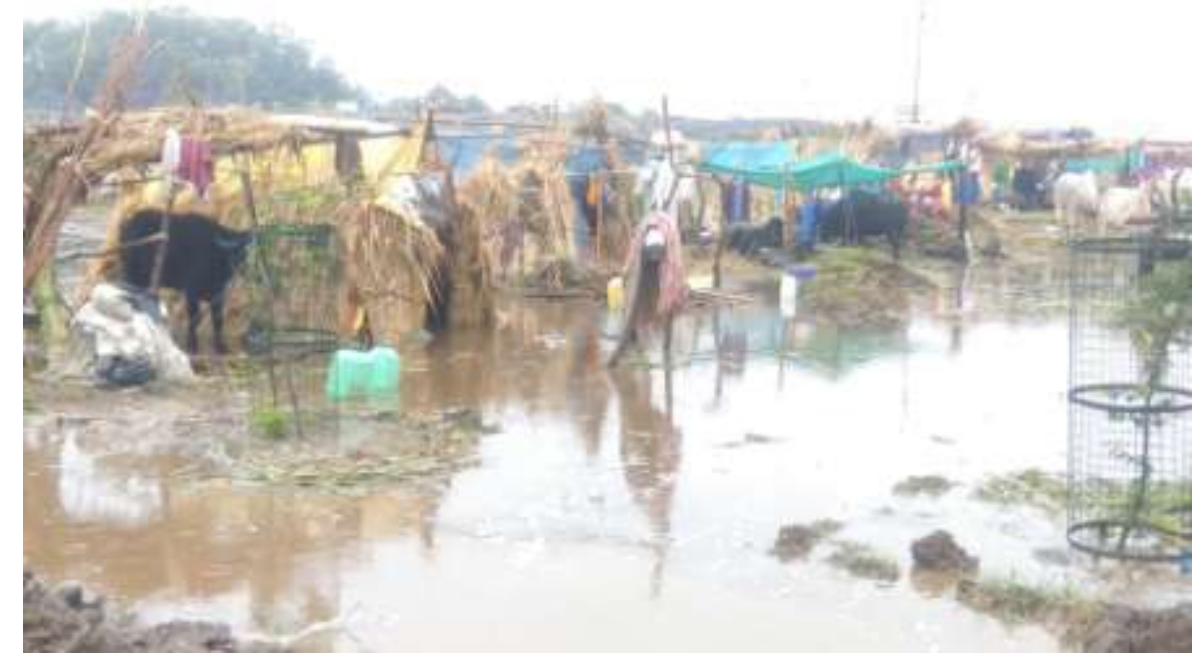

Photo 1: Camp at Someshwar Sugar Factory near Pune (by Akash Sawalkar)

The retreating and untimely monsoon affects the living of the labourers a lot. In November 2018, the heavy rains badly affected the laborers' makeshift homes The labourers couldn't enter their homes and were displaced for a couple of days. The makeshift homes were half-drowned into the water with the season's grains and other material brought from the source became wet and useless. They were not compensated for this by the sugar mill or the contractors. 

Reflections

There was a toli (group of cane cutting families) at village Patkul in Solapur district. There was a woman, Ramatai, who was a seven-and-a-half-month pregnant and she used to harvest with her drunkard husband. One day while at the work site, she started suffering from stomach ache that led to water discharge and had to come back home. Being the only person to cook for her two-and-a-half-year-old son and husband, she went for cutting the firewood. There she fell down and hurt her leg. She came back to the hut and slept for some time. By the time her husband and other labourers came from the site late in the evening, she had become unconscious so the labourers started to look for a borrowed bike from the nearby houses to take her to the nearest village clinic which was some eight kilometer away from the camp. The road to the clinic was a very bumpy one. Eventually, the filmmaker managed to take her took to the clinic around $9 \mathrm{pm}$ in a car to a tiny clinic. The doctor had only some primary medication. The doctor recommended her immediate admission to the government hospital in Pandharpur, the nearest town around 20 kilometers away. He cautioned her to rest for a week else she could face a pre-mature delivery. But her husband had no luxury to miss his work and sit with her for a few days without work. So, we took her back to the camp. The next morning her husband dropped Ramatai and their son at their village around 300 kilometer away from the destination by a ST bus and came back on the same night to resume work from the next day. The labourers informed that they could not ask the contractor for any favour like taking them to the hospital or dropping them to their homes in a time of need also who instead of support would get angry at them for missing their work at site and cut their wages.

This toli migrated internally to their next destination around 15-kilometer away on the night of $31^{\text {st }}$ December 2018. There was an 85-year old woman and her one-and-a-half-year-old grandson. All the labourers especially the old lady and the child shivered a lot as their clothes got wet due to the 7-degree Celsius temperature. They cried their hearts out during their journey with pain and fear. They reached their next destination by midnight when the world started celebrating and welcoming the new year with firecrackers. As their clothes were wet due to the fog in the air, they spent the rest of the night just by sitting near the firewood and their makeshift homes were to be ready in a day or two.

Ashrobanath (14) from the same toli was going to school at his uncle's village. But when his mother started suffering from some unrevealed disease and could not work on par with other women, Ashrobanath joined them at the harvesting site by leaving his school in between. He said, "if you miss your school, you can manage it later. But if you lose your mother, she is not going to come back". Ashrobanath's younger sister Shivani (4) was also there with them.

In a different toli, there was Anil (6), who cut his left-hand thumb while cutting sugarcane. He was from Dhule district and belonged to a tribal community who are less skilled than the traditional cane harvesters. They are exploited more due to different language, culture and being new and unskilled in their work in comparison with the traditional harvesters.

Sanjivani (14) also wanted to stay back in her village for school but her mother too had become old and she needed a helping hand at work and home so she got Sanjivani with her. Her father had stopped cane cutting for a few years and decided not to go for it but in the year 2018 he had to take some advance from the contractor due to the severe drought situation in his region. Sanjivani said that she dreamt of completing her education and become a singer. The possibility of her dream looked impractical in that surrounding.

These labourer couples do not get any privacy as their huts are just next to each other and they sleep with their children in a small hut generally of 6 feet long. The couples are denied their 
fundamental right to keep physical contact in this situation. A labourer told the researcher 'we keep our sleep at our original home when we come here for six to eight months.' Perhaps the same is true for their sexual lives too. If there's an urge to do so, the couple goes to the nearby field in the dark. Women wake up very early in the morning as they have to go to toilet in open places, take bath in open bathrooms before men wake up and start doing their natural activities.

The researcher met many women who had removed their wombs for various reasons. One of the most prominent reasons was that they menstruate during work that impacts the work or sometimes the women labourer may miss the work for a couple of days. The sugar mills are working every day for six to eight months. So, the contractors do not want them to miss the work. The commercial doctors instil fear in the minds of vulnerable women by saying that they risk getting cancer if they do not remove their wombs. Unwarranted hysterectomies are the result of work-related pressures imposed on women, plus a grossly unregulated private medical sector and exploitative contractors and sugar factory owners. (Chatterjee, 2019). Around 30\% of the women labourers from Beed district have removed their wombs for health reasons or for a 'smooth working'. The women labourers informed that hysterectomy was the decision of their families and contractors never advised or forced them in doing so.

\section{CONCLUSION}

The living and working conditions of the cane harvesting labourers are harsher than imagination. On one hand, we experience the fortune of the sugar industry and on the other hand, in the same vicinity, we meet the fate of the cane harvesting labourers. The contrast is heart wrenching but systematically ignored. Woman, child and old labourers are exploited to the fullest inhuman

possibilities. The labourers are very much part of the industry but are they really part of the industry?

\section{REFERENCES:}

Bunsha, D. (2002) Crushed Labour. Frontline, Volume 19(Issue 03).

Deshingkar, Priya \& Start, Daniel (2003) Seasonal Migration for Livelihoods in India: Coping, Accumulation and Exclusion. Overseas Development Institute, London. 01-31. Doi: 8.2003.

Jugale, V. B. (2012) Migrant Workers of Sugar Industry in Maharashtra. Journal of Economic and Social Development, Vol. VIII(No. 1). 15-24. Retrieved from http://www.iesd.org.in/jesd/Journal\%2opdf/2012VIII-1\%20V\%20B\%2oJugale.pdf

Pakhare, A., Pawar, R., Lokhande, G. \& Datta, S. S. (2014) Does Seasonal Migration for Sugarcane Harvesting Influence Routine Immunization Coverage? A Cross-Sectional Study from

Rural Maharashtra. Indian Journal of Public Health, Volume 58(Issue 2). 116-120. Doi: 6.2014

Shiralkar, K., Kulkarni, M., Ghotale, V. and Gholave S. (2018) Ustodni Majurancha Sthalantarit Jagna - God Sakhrechi Kadu Kahani (2018). Pune, MH, Unique Academy

Tokle, Manisha (2018). Ustod Mahilanchya Samasya. Milun Saryajani, (September 2018), p.48-5o.

Patkar, Medha (2019, Feb 24). Mansacha Ras Pinare Us. Daily Loksatta ], Lokrang, p. 2. 

Reflections

Mithunchandra Chaudhari is a teacher, filmmaker and poet. Presently he teaches at Symbiosis Institute of Media \& Communication, Pune and is also pursuing a practice-based PhD from there. He is the recipient of the US-India Research Grant (2018-2020) for Interactive Documentary as a Method for Civic Engagement. His short fiction and documentary films were selected at many prestigious national and international film festivals. His short fiction 'Paywat' won the 'Best Educational Film' Award at 63rd National Film Awards 2015. He was an IFFI 2017 jury member for non-feature films in the Indian Panorama section. He has assisted the feature films 'Fandry' \& 'Sairat' directed by Nagraj Manjule.

Dr. Ruchi Jaggi is Professor and Director of Symbiosis Institute of Media and Communication, Symbiosis International (Deemed University), Pune, India. She is also the Dean of the Faculty of Media and Communication, Symbiosis International University. She teaches courses in Media and Culture Studies and Research Methods. Her research interests include media representations, children and media, popular culture analysis, media and children, television studies, journalism studies, media literacy, streaming platforms and emerging discourses of identity on the new media. Ruchi is also a recipient of a research grant on a project on Interactive Documentaries in partnership with Salisbury University, Maryland, USA under USIEF's U.S.-India 21st Century Knowledge Initiative awards from September 2018 to August 2020. She has also been awarded the 'Woman Leadership Award' in 2018 and 2020, respectively. Ruchi is also the ViceChair of the Media Education Research Section of the International Association of Media and Communication Research (IAMCR). 